Volume 1 Issue 1

June 2016

\title{
E-learning on the road: online learning and social media for continuous professional competency.
}

\author{
Alan M. Batt GradCertICP MSc(c) \\ Faculty of Health Sciences and Human Services, Fanshawe College, London, ON, Canada. \\ Centre for Paramedic Education and Research, Hamilton Health Sciences, ON, Canada. \\ National Ambulance LLC, Abu Dhabi, United Arab Emirates. \\ McNally Centre for Paramedicine Research, Toronto, ON, Canada. \\ Centre for Prehospital Research, Graduate Entry Medical School, University of Limerick, Ireland. \\ Niamh M. Cummins BSc MSc PhD \\ Centre for Prehospital Research, Graduate Entry Medical School, University of Limerick, Ireland.
}

\section{Recommended Citation}

Batt AM and Cummins NM. E-learning on the road: online learning and social media for continuous professional competency. Irish Journal of Paramedicine. 2016 Jun; 1(1)

\footnotetext{
This is an Open Access article distributed under the terms of the Creative Commons Attribution-Non-Commercial-ShareAlike 4.0 International (http://creativecommons.org/licenses/by-nc-sa/4.0/), which permits use, distribution, and reproduction in any medium, provided the original work and any attributes thereof are properly cited, are distributed under the same licence, and that the work is not used for commercial purposes.
} 
ORIGINAL RESEARCH

\section{E-learning on the road: online learning and social media for continuous professional competency.}

Alan M. Batt GradCertICP MSc(c) ${ }^{1-4}$, Niamh M. Cummins BSc MSc PhD ${ }^{4}$

1. Fanshawe College, London, ON, Canada; 2. Centre for Paramedic Education and Research, Hamilton Health Sciences, ON, Canada; 3. National Ambulance LLC, Abu Dhabi, United Arab Emirates; 4. Centre for Prehospital Research, Graduate Entry Medical School, University of Limerick, Ireland.

Received: 10 March $2016 \quad$ Revised: 21 March 2016; 24 April $2016 \quad$ Accepted: 15 May $2016 \quad$ Published: 08 June 2016

Correspondence: Alan M. Batt, Fanshawe College,1001 Fanshawe College Blvd, London, ON N5Y5R6, Canada. Email: abatt@fanshawec.ca

Abstract

\section{Background}

The impact of social media and online learning in health professions education has previously shown generally positive results in medical, nursing and pharmacy students. To date there has not been any extensive research into social media and online learning use by prehospital health care professionals such as paramedics.

\section{Aim \& Methods}

We sought to identify the extent to which Irish pre-hospital practitioners make use of online learning and social media for continuous professional competency (CPC), and the means by which they do so. A cross-sectional online survey of practitioners was conducted to obtain both quantitative and qualitative data. The release of the survey was in a controlled manner to PHECC registrants via various channels. Participation was voluntary and anonymous.

\section{Results}

A total of 248 respondents completed the survey in full by closing date of 31 March 2015, representing $5.4 \%$ of all registrants $(n=4,555)$. $77 \%$ of respondents were male, and the majority were registered as Emergency Medical Technicians (49\%), followed by Advanced Paramedics (26\%). Over $78 \%$ of respondents used a mobile device in the course of their clinical duties; the majority used an iOS device. Social media and online learning were considered learning tools by over $75 \%$ of respondents, and over $74 \%$ agreed they should be further incorporated into prehospital education. The most popular platforms for CPC activities were YouTube and Facebook. The majority of respondents (88\%) viewed self-directed activities to constitute continuous professional development activity, but $64 \%$ felt that an activity that resulted in the awarding of a certificate was better value. Over $90 \%$ of respondents had previous experience with online learning, but only $42 \%$ indicated they had previously purchased or paid for online learning.

\section{Conclusion}

Prehospital practitioners in Ireland in the population studied consider online learning and social media acceptable for CPC purposes. The main social media outlets used by PHECC registrants are YouTube and Facebook. Practitioners consider online learning that awards a certificate to be better value than self-directed activities. The majority have previous experience of online learning. The results of this study can be used to ensure educational interventions are targeted at practitioners through the correct channels.

Keywords: CPC; paramedic; EMT; social media; e-learning; online learning; Ireland

\section{Introduction}

The impact that social media and the internet have on our everyday lives is apparent, with a large percentage of the population having multiple social media network accounts. Websites such as Facebook and Twitter have transformed personal communication and redefined social interaction. An Ipsos Market Research Board of Ireland (MRBI) Social Networking Quarterly poll in August/September 2015 shows that $59 \%$ of Irish adults have a Facebook account, 28\% have a Twitter account, 23\% have a LinkedIn account and $21 \%$ have a Google+ account.(1) These figures have fluctuated only slightly since August 2013, indicating a consistent market penetration. In addition, many people, in particular those with a Facebook account, use it on a daily basis.(1)

The impact of social media and online learning on paramedic education is not well researched, but studies in other healthcare professions to date are encouraging, showing generally positive results.(2,3) Healthcare professional students have responded favourably to the blending of elearning into clinical teaching in medical, nursing and allied healthcare fields. Jaffar (2014) studied the impact of anatomy and physiology education for medical students through Facebook, with the majority of students surveyed agreeing that Facebook could be a suitable learning environment.(4)

Pharmacy students surveyed in 2012 about a Facebook learning page in their program in the USA responded favourably to its addition, and the majority stated that they were more likely to post on Facebook rather than on Blackboard (the official university learning management system) and that they were more likely to see and read posts on Facebook than on Blackboard.(5) Nursing students in the UK showed similar usage, and statements provided by 
students when surveyed about the use of Facebook included "[I'm] used to using Facebook" and "[It is] easily accessed at any time of day".(6)

Social media and e-learning can also facilitate asynchronous learning, or the concept of individual interactive instruction which, is defined as "individualized learning away from groups of similar-level learners, which allows learners to consume material at their own pace on their own timetable".(7) Previous research has shown that newly acquired knowledge through e-learning can be successfully adopted and transferred to clinical practice, making elearning a potentially useful tool for prehospital practitioners. Social media also allows for individuals who cannot attend conferences, seminars and other live continuous professional competency (CPC) activities to stay current and informed of the latest developments at these events.

Since the advent of CPC requirements for registered prehospital care practitioners in Ireland in recent years $(8,9)$, educational institutions and practitioners themselves have been investigating the most effective methods for undertaking CPC activities. Continuing education in Ireland for prehospital care practitioners has previously been delivered through online learning means such as the Pre-Hospital Emergency Care Council (PHECC) eLearning Academy. However, there has not been any extensive research conducted into the use of social media and online learning by prehospital healthcare professionals such as Emergency Medical Technicians (EMTs) and paramedics in Ireland outside of this venue.

\section{Aim}

The aim of this study was to identify the extent to which Irish pre-hospital practitioners make use of online learning and social media for CPC purposes, and the means by which they do so.

\section{Methods}

A cross-sectional, anonymous, online survey was constructed to obtain quantitative and qualitative data. Nationwide ethics approval was obtained from the Research Ethics Committee of the Health Services Executive, University Hospitals Limerick, Limerick, Ireland.

No previous questionnaires investigating paramedics or other healthcare professions similar use of social media for continuous professional development were identified in the literature. The survey tool consisted of 29 questions (Appendix 1). Respondents were provided with a concise, unbiased explanation of the survey topic. Participation was voluntary and anonymous. Consent to participate was assumed once the survey was accessed and recorded. Data was collected and reviewed by the researchers, and no thirdparty had access to the stored data.

The questionnaire was designed to yield data to evaluate the incidence, relevance and opinions of Irish prehospital practitioners on social media and online learning for continuous professional competency purposes

The participants were asked to complete 29 questions, including some basic demographic data (gender, age bracket, qualification level and length of time qualified). They were then asked to rate statements on a five-point Likert-scale style ranging from 'strongly disagree' [1] to 'strongly agree' [5] (quantitative ) and free text written comments to open-ended questions (qualitative) responses. They were also asked a number of closed 'Yes/No' questions relating to use of certain social media platforms. To make analysis more meaningful, responses to the five-point Likert scale were analysed using three options, 'strongly agree/agree', 'undecided' and 'strongly disagree/disagree'. Qualitative data was analysed and grouped into themes based on frequency.

The link to this questionnaire was distributed to PHECC Registered EMTs, Paramedics and Advanced Paramedics through the Centre for Prehospital Research mailing list, the Irish College of Paramedics membership database, training officers and education managers of statutory and voluntary services, and direct mailings to individual practitioners where possible. As a follow-up, reminder emails which have been shown to be beneficial in improving the response rate (10) were emailed four weeks later to the same group.

The survey software used was LimeSurvey, a selfhosted secure survey platform. All options to collect identifiable data such as date and time of submission, IP address, personal information etc. were disabled. The survey tool was piloted by ten EMTs and paramedics. These responses were subsequently excluded from analysis.

The data were downloaded to an electronic data file and quantitative analysis was performed using Statistical Packages for the Social Sciences (IBM SPSS version 20.0).

Presented now is an overview of the results of the study. Quantitative data is related in percentages relative to the number of survey respondents. To add further detail, a selection of the qualitative data relating to identified themes has been selected by the authors.

\section{Results}

Demographics

A total of 262 respondents replied to the survey by the closing date of 31 March 2015. Of these, 248 respondents completed the survey in full. A further 14 only provided partial responses and were excluded from analysis. The results presented below are based on the 248 complete responses received. These responses represent $5.4 \%$ of the total PHECC register, correct as of 2nd April $2015(\mathrm{n}=4,555)$.

Of the respondents to the survey, 191 were male $(77 \%)$ and 57 were female $(23 \%)$. The majority of respondents were aged $35-44$ years $(n=81,33 \%)$, followed by 45-54 years old $(n=70,28 \%)$, and $25-34$ years old $(n=63$, $25 \%)$. Twenty-five respondents were aged over 55 (10\%) and nine were aged under $24(4 \%)$. A total of 233 respondents were resident in Ireland (94\%) with the majority of the 
foreign based respondents resident in either the United Kingdom $(n=6,2 \%)$ or the United Arab Emirates $(n=3,1 \%)$. (Figure 1)

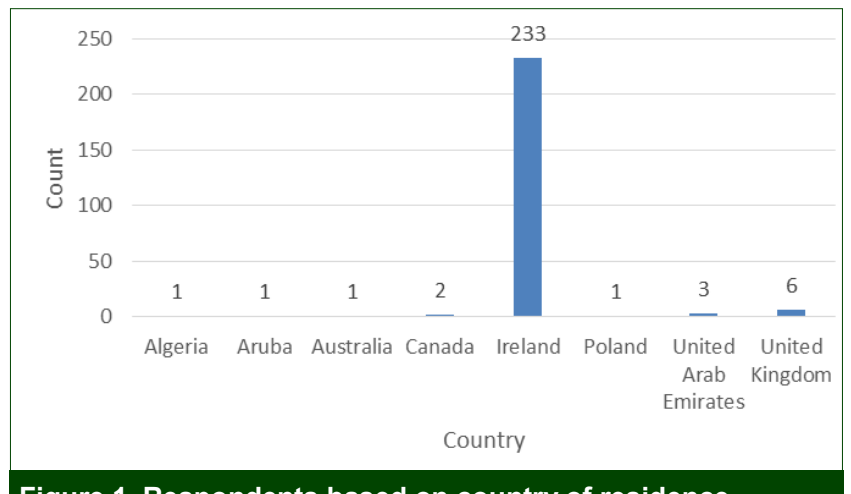

\section{Figure 1. Respondents based on country of residence}

The majority of respondents were resident in counties Dublin or Cork, followed by counties Limerick, Meath, Wicklow and Galway. The majority of respondents $(n=121,49 \%)$ were registered at the Emergency Medical Technician level, with $63(25 \%)$ registered at Paramedic level (or student/intern level), and 64 (26\%) registered at Advanced Paramedic level (or student/intern level). (Figure 2) These figures represent $6 \%$ of all EMTs $(n=2,007), 3 \%$ of all Paramedics $(n=2,129)$ and $15 \%$ of all Advanced Paramedics $(n=419)$ registered with PHECC as of April 2015.

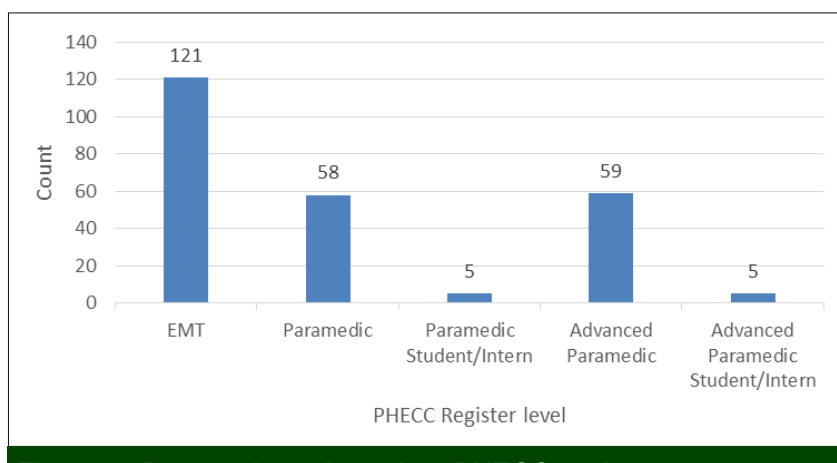

Figure 2. Respondents based on PHECC register status

Median length of qualification was 5 years (range 1-35 years). A total of 63 respondents had completed, or were currently pursuing postgraduate level studies of some description (25.4\%).

The majority of respondents practiced primarily for the National Ambulance Service ( $\mathrm{n}=93$ ) followed by the Irish Red Cross $(n=48)$, Order of Malta Ireland $(n=39)$ and Civil Defence Ireland $(n=16)$. The majority of respondents $(n=144$, $58 \%$ ) did not practice with a second organisation. Those who did mainly practiced with one of the voluntary organisations as a secondary organisation (Irish Red Cross, Civil Defence Ireland, St. John Ambulance Brigade or Order of Malta) Ireland.

\section{Mobile device use}

A total of 195 respondents (79\%) indicated they used a smartphone or tablet device in the course of their clinical practice. The majority of these $(n=117,47.1 \%)$ were devices running iOS, with 84 respondents (34\%) using devices running Android operating system. Six respondents used devices running Windows Phone or Windows 8. Only two respondents used a Blackberry device. (Some users used more than one device, hence the overall numbers exceed the total respondents to this question). Over $50 \%$ of respondents used these devices to complete CPC activities during "downtime" such as between calls.

\section{Social media and e-learning}

Social media and online learning were considered learning tools by over $75 \%$ of respondents $(n=187)$. When asked if social media or online learning should be further incorporated into paramedic education, 74\% strongly agreed/ agreed $(n=183), 9 \%$ disagreed/strongly disagreed $(n=22)$ and $17 \%(n=43)$ were unsure. A selection of the participants' comments are listed in Table 1.

When the advantages and disadvantages to online or social media-based learning were investigated, over $80 \%$ of respondents provided feedback. Some of their responses are outlined in Table 2.

Over $88 \%$ of respondents $(n=219)$ viewed selfdirected activities (such as reading a blog, watching a webcast, listening to a podcast etc.) to constitute continuous professional development activity. However 64\% of respondents $(n=159)$ were of the opinion that online learning activities that awarded a certificate or statement of achievement were better 'value' than those that don't. The majority of respondents $(n=155,63 \%)$ used webcasts for CPC purposes, followed by podcasts $(\mathrm{n}=111,45 \%)$ and blogs $(\mathrm{n}=100,40 \%)$.

Over $90 \%$ of respondents had previous experience with online learning $(n=225)$. Only $106(43 \%)$ previously purchased access to online learning materials. A total of $27 \%$ $(n=66)$ indicated they had an active personal subscription to any journal, and these subscriptions ranged from the Journal of Emergency Medical Services (JEMS) to the British Medical Journal (BMJ).

The majority of respondents had a Facebook account $(\mathrm{n}=206,83 \%)$, followed by LinkedIn $(\mathrm{n}=137,55 \%)$, YouTube accounts $(n=131,53 \%)$, Twitter $(n=121,48.8 \%)$ and Google $+(n=113,46 \%)$. Only $11 \%$ of respondents $(n=28)$ had an account with a massive open online course (MOOC) provider and a total of 73 respondents $(29 \%)$ had access to an Athens account.

When the use of these accounts for CPC activities was investigated, the most commonly used platform for CPC activities was YouTube $(\mathrm{n}=87,35 \%)$ followed by Facebook $(\mathrm{n}=78,35 \%)$, Athens $(\mathrm{n}=65,26 \%)$ Twitter $(\mathrm{n}=56,22.5 \%)$, LinkedIn $(n=44,17.7 \%)$, Google $+(n=32,12.9 \%)$ and MOOC providers $(n=25,10 \%)$.

\section{Discussion}

E-learning has previously been identified by Irish practitioners as a successful tool for delivery of prehospital educational information.(11) However, Irish prehospital 


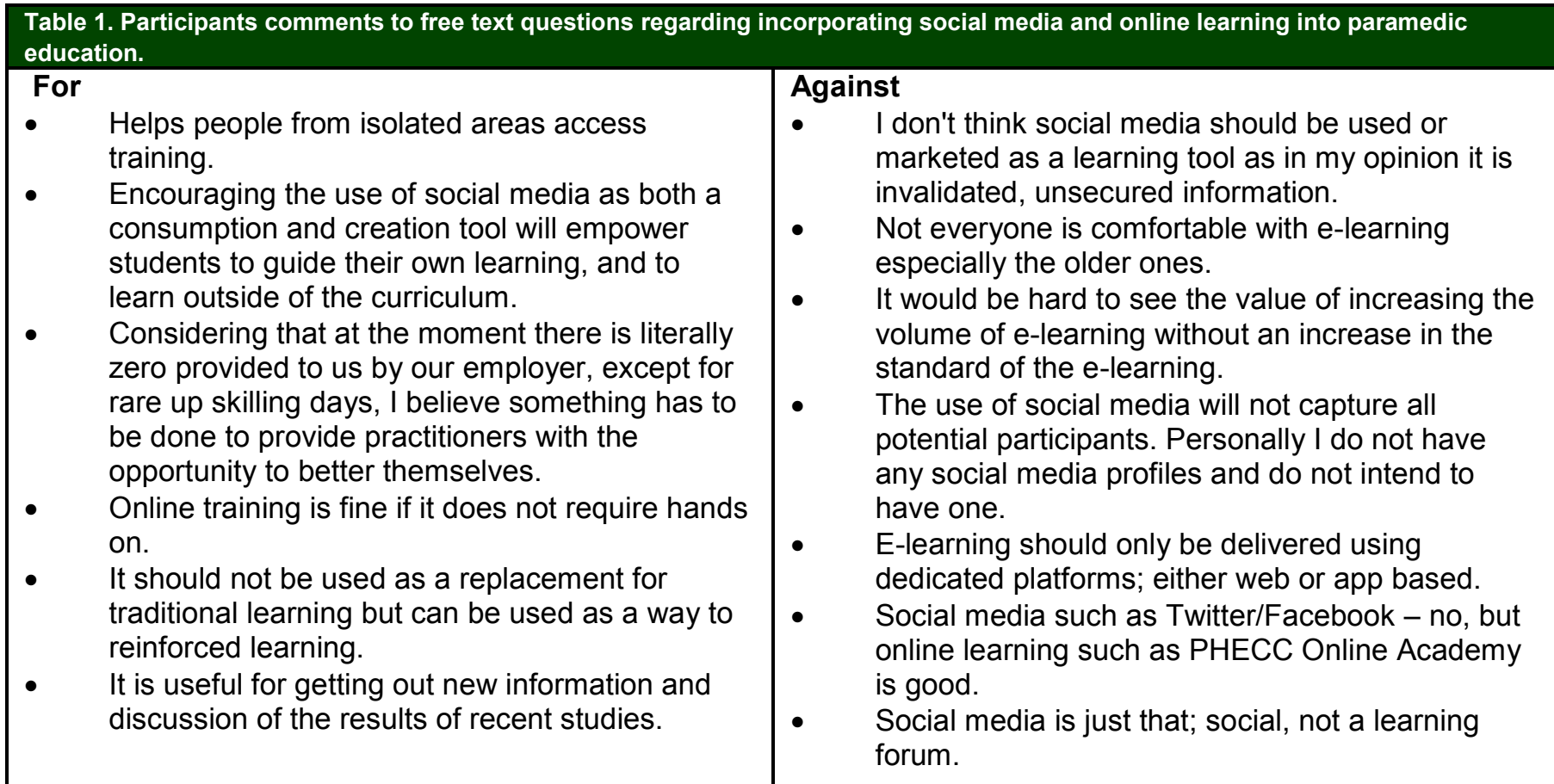

Table 2. Participants comments to free text questions regarding advantages and disadvantages to online learning and social media

\section{Advantages}

- $\quad$ Ease of access. Can be done on days off, on breaks, down time on night shifts etc.

- $\quad$ Asynchronous learning, allows for development even when committed to a full-time position.

- $\quad$ Self-paced, interactive learning.

- $\quad$ Exactly the same course taught to everyone - no local misrepresentations.

- $\quad$ Don't have to give up "personal time" to travel to and attend training.

- $\quad$ More time efficient as not wasting time sifting for information through traditional sources such as text books.

- $\quad$ Clinical experts of all levels imparting their knowledge.

\author{
Disadvantages \\ - $\quad$ Can lack structure, information overload. \\ - $\quad$ Less face to face time with tutors. \\ - $\quad$ Some people don't have the IT skills to access it. \\ - $\quad$ Easy to lose focus. \\ - $\quad$ Need for a computer and good broadband \\ connection. \\ - Quality of educational material varies \\ enormously. \\ - It is not peer reviewed or subject to the same \\ standards as published material. \\ - $\quad$ Management see it as a tool to replace direct \\ learning. \\ - $\quad$ Access to broadband in rural areas
}

practitioners consider e-learning curricula without practical components to be irrelevant, but welcome access to elearning when supplemented by related practical modules. $(8,9)$ This theme was also highlighted in the qualitative data analysed in this survey.

Some of the results obtained in our study surrounding social media use were not surprising based on anecdotal interactions with prehospital care providers in Ireland regarding the topic. The vast majority of respondents had a Facebook account, and they stated it was very easy or easy to use. However, less than one-quarter of respondents felt it was meeting their learning needs, which potentially indicates a lack of engagement by learning material providers with the Facebook platform. We are not aware of any particular educational activities targeted at Irish prehospital care providers that are delivered or facilitated through Facebook. The results regarding prevalence of other social media account use are of interest. Twitter, LinkedIn and YouTube present further potential areas for engaging with prehospital care practitioners in Ireland.
The free open access medical education (FOAM) community is involved in the sharing of resources including links to blogs, podcasts and other freely accessible educational materials. The sharing of content on Twitter has been central to the continued development of the FOAM community through the use of several hashtags such as \#FOAMed.(12) The \#FOAMems Twitter hashtag was also registered in 2014, to facilitate discussion around prehospital care topics on Twitter. There have been almost 60,000 tweets which include this hashtag with nearly 82 million views since 2014, generated by almost 7,500 Twitter users.(13) In addition, since completion of this study, the \#IrishEMS weekly tweet chat was launched in late 2015 where users engage in weekly themed Twitter discussions around issues pertaining to prehospital care in Ireland. This has resulted in almost 6,000 tweets with over 6.5 million views from 562 users since late 2015.(14) As a result of these initiatives, the use of Twitter by Irish prehospital care practitioners is likely much higher today than the results of this study would indicate. 
Table 3. CPC activity guidance outlined by PHECC (13) for Emergency Medical Technicians

\begin{tabular}{|c|c|c|}
\hline Activity & $\begin{array}{l}\text { CPC points } \\
\text { awarded }\end{array}$ & Evidence \\
\hline $\begin{array}{l}\text { CPC related training programme provided by training } \\
\text { organisations or programmes accredited by other professional } \\
\text { organisations (for example, An Bord Altranais, Irish College of } \\
\text { General Practitioners (ICGP) and so on) }\end{array}$ & $\begin{array}{l}1 \text { point per } \\
\text { hour }\end{array}$ & Certificate \\
\hline Case study & 2 points & $\begin{array}{l}\text { Case study on an incident, } \\
\text { condition } \\
\text { or injury you have encountered }\end{array}$ \\
\hline Reflection on incident & 2 points & $\begin{array}{l}\text { A document containing the } \\
\text { main points you have learned }\end{array}$ \\
\hline Seminars and conferences & $\begin{array}{l}1 \text { point per } \\
\text { hour }\end{array}$ & $\begin{array}{l}\text { Details of the seminar you have } \\
\text { been to with a review of the key } \\
\text { points you have learned }\end{array}$ \\
\hline $\begin{array}{l}\text { Programmes such as ACLS, PALS, PHTLS, PEPP, ATC, } \\
\text { MIMMS, ITLS, Wilderness EMT, ATLS, AMLS and so on }\end{array}$ & $\begin{array}{l}1 \text { point per } \\
\text { hour }\end{array}$ & Certificate \\
\hline Journal article review & 2 points & $\begin{array}{l}\text { Critical appraisal of a journal } \\
\text { article }\end{array}$ \\
\hline Electronic learning/on-line learning - related to practice & $\begin{array}{l}1 \text { point per } \\
\text { hour }\end{array}$ & Printed certificate from site \\
\hline $\begin{array}{l}\text { Mentoring a student or being mentored on any experiential/ } \\
\text { operational ambulance, response vehicle placement. }\end{array}$ & $\begin{array}{l}1 \text { point per } \\
\text { hour }\end{array}$ & $\begin{array}{l}\text { Documented evidence of } \\
\text { placement, signed by a } \\
\text { paramedic or advanced } \\
\text { paramedic }\end{array}$ \\
\hline
\end{tabular}

YouTube was identified as the single largest platform used for CPC purposes in this study. However, the accuracy of medical information provided on the internet, and in particular videos on YouTube needs to be further investigated.(15) For example, recent reviews have found that approximately $13 \%$ of videos relating to ECG interpretation were misleading (16), almost $50 \%$ of videos discussing management of peripheral neuropathy were not discussing evidence-based recommendations (17) and $66 \%$ of videos pertaining to seizure management did not depict a seizure. (18) A review by Duncan et al showed that the quality of the majority of clinical skills videos on YouTube was questionable, with very few being graded as completely accurate.(19)

One such initiative which is harnessing the popularity of YouTube access for CPC activities, and providing viewers with accurate evidence based information is the O'Brien Institute (OBI) CPC Nights (OBI-CPC) event. Live educational sessions are broadcast to several satellite locations around Ireland, and made available for personal viewing via YouTube. Participants can sign up and attend for free, and a certificate of attendance is issued after the event for CPC records. To date there have been eight events organised, with 24 unique topics delivered. Since June 2014 there have been over 3350 views of the eight events on YouTube (live or recorded), combined with 1,244 in person attendances at the live-event or at a satellite location.(20)

As our study has shown, the majority of Irish prehospital care practitioners surveyed prefer CPC activities that results in the awarding of a certificate. This is a somewhat antiquated view of CPC activities, and highlights a potential area for improvement. PHECC have previously issued guidance on CPC activities to practitioners (21) which clearly outlines several options such as journal article review, reflection, case study completion, mentoring and other noncertified activities (Table 3). While the authors wholeheartedly agree with the collection of evidence surrounding CPC activities, the emphasis and practitioner preference displayed regarding perceived value of certificates may promote a culture of "tick-the-box" course attendance that may not necessarily meet the learning needs of the individual practitioner. Evidence of completed CPC activities can take many forms, and does not have to explicitly include the issuance of a certificate.

The majority of practitioners reported used a smartphone during their clinical practice (to reference guidelines and medication information for example), but over half of the respondents in this study also used their smartphone or mobile device to complete CPC activities during "downtime". Ensuring that learning and CPC resources can be accessed easily using these devices should theoretically make it easier for practitioners to undertake CPC activities.

Equity of access to online learning was a major theme discovered on analysis of qualitative responses to this survey. An estimated 1.7 million Irish people live in rural areas, which is almost $37 \%$ of the total population (4.6 million).(22) Total broadband penetration in Ireland is approximately $80 \%$ 
(23), which still leaves a substantial proportion of the population without access to reliable high-speed internet access. Latest estimates from the Central Statistics Office indicate approximately 1,600 households do not have a broadband connection.(24) Practitioners living in these areas may be limited to completing CPC activities on work computers, and workload may prevent this from being a realistic option.

The low prevalence of Athens account availability is an area that needs to be further researched. Athens is an online electronic resource login that provides access to electronic journals, electronic books, and databases including Medline, CINAHL and Embase. The Health Service Executive (HSE) provide access to a personal OpenAthens account for every employee through their local HSE library. Resources available through this account vary extensively on a regional basis. Some level of training is required in order to maximise the usefulness of an Athens account, and lack of access to this training may be one of the reasons for poor uptake of Athens account access.

PHECC registered Practitioners working within Dublin Fire Brigade, or the voluntary organisations are not provided with access to an OpenAthens account by their organisation. At the time this study was conducted, PHECC provided a free personal subscription to the Journal of Paramedic Practice to all registrants, however our results indicate practitioners were not aware of this, or chose not to redeem it.

Our study has several limitations which need to be highlighted. A sample size of 355 respondents was required in order to analyse results for statistical significance. The fact that our 248 survey participants only represent $5.4 \%$ of the overall register at the time the survey was conducted is an obvious limitation, and the results outlined cannot show statistical significance. A forum to contact all PHECC registrants through official PHECC channels for research purposes is currently unavailable. The link to survey completion was distributed via email, which may lead to the introduction of selection bias. However, the link was not distributed on social media in order to control its distribution to PHECC registered practitioners only.

The majority of respondents were male $77 \%(n=191)$ which could potentially affect results regarding platform preference and usage. To put this in context however, prehospital care provision in Ireland is a predominantly male profession, although the number of females entering the profession is increasing steadily. It is uncertain exactly how this may influence the results in terms of platform usage and preference. No responses were received from practitioners employed with Dublin Fire Brigade, the second largest employer of paramedics and advanced paramedics in Ireland. The reasons for this are unclear as the link was distributed to identified personnel within the organisation.

No responses were received from providers resident in counties Antrim, Armagh, Carlow, Derry, Down, Fermanagh,
Roscommon or Tyrone. Six of these counties are located in Northern Ireland, and Paramedics practicing in these five counties would be registered with the Health and Care Professions Council (HCPC) of the United Kingdom. This does not explain the lack of responses from Carlow and Roscommon, where providers would be registered with PHECC.

A significant number of respondents represented a younger population (with $62 \%$ under the age of forty-four years) and this would may also have influenced the results. This particular population may prefer a blended learning approach and may be more amenable to incorporating elearning and social media technology in their learning, given the possibility that they may be more familiar with these technologies.

\section{Recommendations and conclusions}

To date, little research has been conducted with PHECC registered practitioners, and this survey is the first to ascertain the use of online and social media technology by a sample of Irish prehospital practitioners. E-learning is an important and powerful tool for pre-hospital providers for many reasons, including facilitating self-directed learning during "down-time" or whilst at a standby location. It also allows practitioners to plan their own learning, facilitating differing levels of clinical practice and competency.

Learning resources should be targeted at the most commonly utilised platforms, such as Facebook, YouTube and LinkedIn, webcasts and podcasts. The recent surge in Twitter activity also needs to be factored in. It should also be borne in mind that preferences with regards to platform usage can, and do, change with time, and education providers and organisations should ensure they continually assess the needs and wants of their learners. The facilitation of further blended education delivery should be considered by education providers in Ireland. Solutions to ensure equity of access to high-speed, reliable internet in the case of paramedics living or based in rural locations need to be identified.

This study has demonstrated that many Irish prehospital practitioners already use smartphones and tablets during their everyday clinical practice, and providing learning and CPC resources that can be accessed using these devices will make it easier for practitioners to maintain current competency. Engaging with the active FOAM community may also benefit prehospital care practitioners in Ireland, and their continued engagement with and sharing of prehospital specific materials is encouraging. The results of this study can be used to aid in the development of e-learning and social media educational resources in Ireland in the near future.

\section{Author contributions}

$\mathrm{AB}$ was the principal investigator for the study, principal author of the manuscript and performed the literature review and data analysis. NC developed the study design, validated the literature review, performed data analysis and contributed 
to the final editing.

Source of support/funding: None.

Conflict of interest: $A B$ is Editor of the IJP, creator of the \#FOAMems hashtag, and involved with the administration of the \#IrishEMS weekly chats.

Provenance and review: Not commissioned, peerreviewed.

\section{References}

1. IPSOS/MRBI. Social Networking Quarterly August [Internet]. 2015. Available from: http://ipsosmrbi.com/wpcontent/uploads/2015/11/SN_Aug15.pdf

2. Wolbrink $T$ a, Burns JP. Internet-based learning and applications for critical care medicine. J Intensive Care Med. 2012;27(5):322-32.

3. Gaikwad N, Tankhiwale S. Interactive E-learning module in pharmacology: a pilot project at a rural medical college in India. Perspect Med Educ. 2014;3:15-30.

4. Jaffar AA. Exploring the use of a Facebook page in anatomy education. Anat Sci Educ. United States; 2014;7 (3):199-208.

5. Divall M V, Kirwin JL. Using Facebook to Facilitate Course-Related Discussion Between Students and Faculty Members. Am J Pharm Educ. 2012;76(2):1-5.

6. Morley DA. Supporting student nurses in practice with additional online communication tools. Nurse Educ Pract [Internet]. Elsevier Ltd; 2014;14(1):69-75. Available from: http://www.sciencedirect.com/science/article/pii/

\section{$\underline{\mathrm{S} 1471595313001248}$}

7. Reiter DA, Lakoff DJ, Trueger NS, Shah KH. Individual Interactive Instruction: An Innovative Enhancement to Resident Education. Ann Emerg Med. Elsevier Inc.; 2013;61 (1):110-3.

8. Knox S, Cullen W, Dunne C. Continuous professional competence (CPC) for emergency medical technicians in Ireland: educational needs assessment. BMC Emerg Med. 2013 Jan; 13:25.

9. Knox S, Cullen W, Dunne C. Continuous Professional Competence (CPC) for Irish paramedics and advanced paramedics: a national study. BMC Med Educ. BMC Medical Education; 2014 Jan;14(1):41.

10. Sheehan KB. E-mail Survey Response Rates: A Review. J Comput Commun [Internet]. 2001;6(2):0. Available from: http://dx.doi.org/10.1111/j.1083-6101.2001.tb00117.x

11. Ellis R, Collins N. Scenario-based electronic learning: a viable educational method. J Paramed Pract. 2012;4(2):96104.

12. Nickson CP, Cadogan MD. Free Open Access Medical education (FOAM) for the emergency physician. Emerg Med Australas. 2014;26(1):76-83.

13. Mason P, Batt A, Steary D. \#FOAMems - the impact to date. Irish J Paramed, 2016; 1(S1).

14. Ward J, Batt A, Menzies D. Facilitating Paramedic Continuous Professional Competency: the \#IrishEMS chat. Irish J Paramed, 2016; 1(S1).
15. Eysenbach G, Diepgen TL, Gray JAM, Bonati M, Impicciatore $\mathrm{P}$, Pandolfini $\mathrm{C}$, et al. Towards quality management of medical information on the internet: evaluation, labelling, and filtering of information. BMJ [Internet]. 1998;317(7171):1496-500. Available from: http:// www.bmj.com/cgi/doi/10.1136/bmj.317.7171.1496

16. Akgun T, Karabay CY, Kocabay G, Kalayci A, Oduncu V, Guler A, et al. Learning electrocardiogram on YouTube: How useful is it? J Electrocardiol [Internet]. Elsevier Inc.; 2014;47(1):113-7. Available from: http://dx.doi.org/10.1016/ j.jelectrocard.2013.09.004

17. Gupta H V., Lee RW, Raina SK, Behrle BL, Hinduja A, Mittal MK. Analysis of youtube as a source of information for peripheral neuropathy. Muscle and Nerve. 2015; (October):1-5.

18. Brna PM, Dooley JM, Esser MJ, Perry MS, Gordon KE. Are youtube seizure videos misleading? Neurologists do not always agree. Epilepsy Behav [Internet]. Elsevier Inc.; 2013;29(2):305-7. Available from: http://dx.doi.org/10.1016/ j.yebeh.2013.08.003

19. Duncan I, Yarwood-Ross L, Haigh C. YouTube as a source of clinical skills education. Nurse Educ Today [Internet]. Elsevier Ltd; 2013;33(12):1576-80. Available from: http://dx.doi.org/10.1016/j.nedt.2012.12.013

20. Ellis G and Ryan G. The uptake of online Continuous Professional Competency activity by prehospital care providers. Irish J Paramed, 2016; 1(S1).

21. Knox S (ed). Continuous Professional Competence A guide for Emergency Medical Technicians registered with the Pre-Hospital Emergency Care Council [Internet]. 2013 [cited 2016 Mar 9]. Available from: http:/www.phecit.ie/Images/ PHECC/Register/EMT CPC Guide Nov_2013 V1 PDF.pdf

22. World Bank. Rural Population Estimates [Internet]. 2015 [cited 2016 Mar 1]. Available from: http:// data.worldbank.org/indicator/SP.RUR.TOTL

23. Communications Regulator of Ireland. Communications Market Quarterly Key Data Report - Q1 2015 [Internet]. 2015. Available from: http://www.comreg.ie/ fileupload/ publications/ComReg1549.pdf

24. Central Statistics Office. ICA27: Households with Computer connected or not connected to the Internet [Internet]. 2015. Available from: http://www.cso.ie/px/ pxeirestat/Statire/SelectVarVal/Define.asp?

$\underline{\text { maintable }=\mathrm{ICA} 27 \& \mathrm{PL} \text { anguage }=0}$

How to cite this article: Batt AM and Cummins NM. Elearning on the road: online learning and social media for continuous professional competency. Irish Journal of Paramedicine, 2016; 1(1). 


\section{APPENDICES}

\section{Appendix 1: Survey Tool}

General Demographics

- Gender

- Age Bracket

- Country of residence

- County of residence (if living in Ireland)

- PHECC Register level

- Years since initial NQEMT qualification

- Post-graduate training completed or in progress (e.g. HDip/GradDip EMS, MSc EMS etc.)

- Primary Affiliated Organisation

- Secondary Affiliated Organisation (if any)

\section{Online Learning \& Social Media}

- Do you have previous experience of online learning? Y/N

- Do you consider social media an online learning tool? Y/ $\mathrm{N}$

- In your opinion should more online/ social media learning be incorporated into traditional paramedic education? Y/N (please elaborate)

- In your opinion, what are the main advantages to online/ social media learning? (please elaborate)

- In your opinion, what are the main disadvantages to online/social media learning? (please elaborate)

- Do you consider self-directed activities such as reading a blog article, watching a webcast or listening to a podcast as continuous professional development activity? Y/N

- In your opinion is online learning that results in the awarding of a certificate or statement of achievement better than self-directed activities? Y/N (please elaborate)

- Have you purchased any online learning courses? Y/N

- Do you have accounts for any of the following platforms? Twitter, Facebook, Google +, LinkedIn, YouTube, MOOC Provider (e.g. Coursera), Athens/OpenAthens

- Do you use any of these accounts for continuous professional development or learning purposes? Twitter, Facebook, Google +, LinkedIn, YouTube, MOOC Provider (e.g. Coursera), Athens/OpenAthens

- Please rate each of these platforms on the following (Likert 1-5 scales) Ease of use; Broad access to content; Meets learning needs

- Which of the following do you use for continuous professional development or learning purposes? Blogs; Webcasts; Podcasts; Journals

- Do you have an active personal subscription to any journals (not through Athens account)? Y/N (please elaborate)

\section{Mobile Learning}

- Do you use a smartphone or tablet device in your clinical practice (e.g. drug calculations, reference to guidelines etc.) $\mathrm{Y} / \mathrm{N}$

- If yes, please indicate operating system type: iOS;
Android; Windows Phone; Blackberry; Other

- Do you use this device to complete CPD activities during "downtime" (e.g. time between calls)? Y/N

This is an Open Access article distributed under the terms of the Creative Commons Attribution-Non-Commercial-ShareAlike 4.0 International (http:// creativecommons.org/licenses/by-nc-sa/4.0/), which permits use, distribution, and reproduction in any medium, provided the original work and any attributes thereof are properly cited, are distributed under the same licence, and that the work is not used for commercial purposes. Content copyright remains with the authors, who grant the IJP a licence to reuse and distribute. 